\title{
The Development of Ternary Nitride Chemistry During the Last Few Decades
}

\author{
Syed Sauban Ghani \\ General Studies Department, Jubail Industrial College, Jubail Industrial City, 31961, KSA \\ * Corresponding author email: saubanghani@gmail.com
}

Received: 09 March 2017 / Revised: 21 March 2017 / Accepted: 26 March 2017 / Published: 28 March 2017

\begin{abstract}
The developments of charged and neutral ternary nitrides during the last few decades have been fast and progressively varied in terms of its preparation, properties, and structures. Ternary metal nitrides of the type $\mathrm{M}_{\mathrm{x}} \mathrm{M}_{\mathrm{y}} \mathrm{N}_{\mathrm{N}} \mathrm{draw}$ significant attention as of their overall superior properties such as mechanical, electrical, magnetic, and catalytic. The progresses in ternary nitrides study have become important in the last few decades up to the degree where the scientist is beginning to associate these compounds in level of certain desired kinds of structures. The current relevance of these nitrides overall depends on the fact that they are very narrowly connected to the pure one-dimensional systems that are immensely examined for their remarkable properties and strongly connected to their short dimensionality. Whether its vital investigations to make presently unidentified ternary nitrides or to evolve innovative and prevailing applications, it is evident by going through the numerous articles in this area that regardless of the striking growth in the preceding few decades, substantial is left to be completed.
\end{abstract}

Keywords: Ternary, Nitrides, Synthesis, Coordination, Structures, Metathesis.

\section{Introduction}

Nitrogen is approximately $79 \%$ of the total air, is omnipresent, and is the key constituent of the atmosphere. Nitrogen as the representative element, and the first element in Group 5A, has a crucial position in chemical compounds. Particularly when it is in the oxidation states of III and $\mathrm{V}$ such as $\mathrm{NO}_{2}$ and $\mathrm{NO}_{3}$ - respectively. Nitrogen readily combines with highly electropositive elements (metals of Group 1), even at room temperature to give nitrides, such as $\mathrm{Li}_{3} \mathrm{~N}$. [1] These nitrides are ionic compounds in which nitrogen is present as a tri negative anion. Thus, lithium nitride may be represented as $\left(\mathrm{Li}^{+}\right)_{3} \mathrm{~N}^{3-}$. These nitrides are crystalline compounds and have high melting points. Nitrogen also have the ability to combine with less electronegative metals like magnesium, calcium, barium and strontium at red heat; with boron and aluminium at bright red heat and with silicon at a white heat, to form their corresponding nitrides. The nitrides formed with metals of Group II are generally ionic while those formed with elements of Group III and Group IV is covalent in character. The nitrides formed with transition metals, such as iron, manganese, molybdenum, tungsten, are true interstitial compounds with nitrogen atoms occupying the 
interstices in the metal structures. These nitrides are extremely hard, have high melting points, possess metallic lustre and metallic conductivity. The oxidation state of nitrogen in the nitrides is also -III; merely a few hundred nitrides have so far been characterized, while for example the next element oxygen is found to form even greater than several thousand oxides. The study of the complex nitride chemistry is even though considerably nascent, with enhanced advancement being made only for the last more than a few years. [2] - [3] Ternary nitrides were first systematically investigated by Juza et al. [4] beginning in the 1940s. The preparation of ionic and covalent ternary and quaternary nitrides gives numerous fascinating tasks for the synthetic inorganic scientific community. The pioneering initiatives in ternary nitride chemistry were originally accomplished in the 6Os, 70 s and early 80 s and over the past half dozen years or so, the systematic study of ternary nitrides has really been accelerated, as Juza and Laurent in Europe and Ward in the USA were among the few who published studies of ternary nitrides. [5] Consequently, ternary nitrides of many metals and non-metals are comparatively well characterised. [6] - [7] The properties of these compounds are generally remarkable and advantageous. The maximum extensively recognized nitrides are ternary nitrides compounds designed by one metal and the nitride anion, $\mathrm{N}^{3}$. They have been mentioned comprehensively in various papers and reviews, among them, the finest being recently published is by D. H. Gregory [8]. Common ternary nitrides may have presented many numbers of exciting and convenient properties till today. But faster development in this field began after introduction and systematic exploitation of several new preparation techniques in the 1980s. Generally, the key to solid state and material chemistry, is its ability to create entirely vital associations among the composition, structure and properties. For over many decades, it is being done for oxide chemistry, for the argument wherever several of the important interactions between fundamental relations of materials are characteristically recognised and acknowledged, with abundant illustrations and instances from where the investigations which form the foundation of inorganic and solid-state chemistry in course book at undergraduate level. We can say that nitride chemistry is still in its initial level with regards to its progress, nevertheless prompted by the recent scientific and eco-friendly drivers and the economic needs to flourish novel materials to market more quickly. The extensive progresses in basic application ranges have been through over a brief passage of time. [9] - [11] During the last several years, nitride field have increased in its own specific way, accepting non-metal and nitridosilicate chemistry, oxynitrides and nitride halides, [12] - [13] sub-nitrides and nitride clusters and the expansion of ternary nitrides as precursors for the materials required for such industries. [14] - [16] It was an accumulation to the research directed into higher order transition metal nitrides and the ternary nitrides. The nitrides consist of virtually very valuable complexes: silicon nitride, $\mathrm{Si}_{3} \mathrm{~N}_{4}$ that has turned out to be an essential nonoxidic material. It's uses starts from ceramic turbochargers and may end at integrated semiconductor modules. [17] - [19] Due to its abnormally enhanced thermal conductivity $\left(285 \mathrm{Wm}^{-1} \mathrm{~K}^{-1}\right)$, aluminium nitride is certain to be used as a substrate material in semiconductor manufacturing. Boron nitride has enormous applications and can be utilized as a high-temperature crucible material, as a lubricant (hexagonal (h)-BN), and in the abrasives sector (cubic (c)-BN). Very recently, h-BN has also turn into gradually more significant in the synthesis of composite materials. While there are still several instances of nitride compounds that stand exclusive by way of their crystal arrangements and stoichiometries, as novel compositions arises, therefore structural tendencies can be initiated and to be recognised. The relationships between compositions to structure or property relationships are not so far well explained in such a fledgling field, on the other hand through the better evidence accessible from synthetic chemists, theorists, physicists and materials scientist's, we can visualize this condition varying in the close forthcoming days. The important aspect in the marginal progress of nitride compounds either single or mixed-anion, is found to be the real test of synthesis and 
S. S. Ghani, J. Mod. Mater.; Vol. 4, Issue 1, pp: 10-15, 2017

characterisation, because nitride compounds are required to be synthesised in air/oxygen free atmospheres. There are several instances or few, the air or humidity sensitivity, imposing air-free conditions and some extra practical abilities. The shortage of nitride materials, in contrast to their oxide equivalents, is the main difficulty in explaining these type of solids, as we are unable to define, systematize, or classify structures geometrically to the level as frequently it is done for the oxides. Henceforth, we can assume that describing their physical properties is not as such easy. Certainly, the finding of novel constituents with useful new properties can be delayed. The current review presents the most recent stage of many fields of the metal ternary nitrides and establishes the vital applications of innumerable metal nitrides.

\section{Synthesis of Ternary Nitrides}

Till today, the number of methods applied for the synthesis of ternary nitrides are still limited. Surprisingly, the enormous number of all the available nitrides were synthesized by applying any of the two well-known methods only. First method is by reacting the already known metal nitride by a metal or alternative metal nitride while in second method, it is the reactions of nitrogen gas or ammonia by the metal powders. The most common approach (Table -1) among the two is the former. As the given reactions generally need a very elevated temperature of about $1100-2100 \mathrm{~K}$, so the method known as inductive effect is applied to bring about the formation of product. The most favourable $\mathrm{Li}_{3} \mathrm{~N}$, is the preliminary component because it has greater stability and comparatively has low melting range of about $1100 \mathrm{~K}$. The low temperature helps in maintaining the speed of the rate of reaction. Subsequently, the number of ternary nitrides that are produced with lithium is much more than any of the metals in group I, II or III. After lithium, ternary nitrides which take the second position are the alkaline earth metal ternary nitrides that are known. This is a confirmation that the reaction method that was adopted was successful. Sometimes, the two different metal powders are reacted directly with nitrogen or sometimes with ammonia has also been employed for the synthesis of ternary nitrides. Similarly, ternary nitrides can also be prepared by the reaction of the binary nitrides. Generally, these compounds are also can be prepared with the heating of the metal powders first in a condition free from air or moisture, after that maintaining the same reaction temperature, nitrogen or ammonia is added. One such illustration of the nitride is $\mathrm{Ba}_{3} \mathrm{FeN}_{3}$ that was prepared using the identical method. [20] The given synthetic procedure is made somewhat more effective by using alkali metal as one of the metals due to many reasons. Some of the reasons is that they used to have their low melting point as well as behave like a reactive flux. Single crystal formations are assisted due to the presence of these alkali metals. The numerous quantities of novel ternary alkali and alkaline earth metal nitrides have been synthesized and were found to be fruitful, which also includes the primarily coated ternary lithium nitride [21] - [24].

\section{Table 1: Common reactions applied for ternary nitride synthesis}

\begin{tabular}{|c|c|c|c|c|c|c|}
\hline a) & $\mathrm{MN}+\mathrm{M}^{\prime} / \mathrm{M}_{\mathrm{y}}^{\prime} \mathrm{N}_{\mathrm{z}}$ & $\rightarrow$ & M - M'-N & & & \\
\hline b) & $M+M^{\prime}$ & $\rightarrow$ & $M-M " \cdot-N$ & + & $\mathrm{H}_{2}$ & \\
\hline c) & $\mathrm{MNH}_{2}+\mathrm{M}$ ', $/ \mathrm{M},{ }_{\mathrm{x}} \mathrm{N}_{\mathrm{y}}$ & $\rightarrow$ & M-M'”-N & + & $\mathrm{H}_{2}$ & \\
\hline d) & $\mathrm{MM}^{\prime \prime} \mathrm{O}_{\mathrm{y}}$ & $\rightarrow$ & $M-M{ }^{\prime}-\mathrm{N}$ & + & $\mathrm{H}_{2} \mathrm{O}$ & + \\
\hline e) & $M-M '{ }^{\prime}-N+M ' / M_{x} N_{y}$ & $\rightarrow$ & M-M''-M'-N & & & \\
\hline
\end{tabular}


The methodologies were subjugated was the inductive effect which involves the presence of metals of like the alkali metals that is helpful in stabilizing the materialization of ternary nitrides which includes the transition metal as well as the non-transition metal [25]. The above approach requires either prolonged treatments by way of heating or involves an amalgamation of extensive period of soaking by the application of high temperature. Nevertheless, putting high temperatures in these reactions certainly take the reaction conditions to contamination because these reactions can be carried out using the crucible and may lead to compositional inhomogeneity. The inhomogeneities of this nature are toxic in various applications where these compounds can be possibly utilized, that may be electronic, mechanical, or magnetic. The significant concern in examining solution chemistry methodologies, especially after the introduction of the sol-gel process, has gain momentum during the preceding few number of years. The unconventional synthetic tactic, exhausting transition metal metallates by few workers, wherein, they have been utilized as precursors to ternary transition metal nitrides. [26] - [27]. A very good illustration for this type of reaction is the preparation of hydrated metal molybdates solution. The hydrated metal molybdates can be synthesized by combining $\mathrm{Na}_{2} \mathrm{MoO}_{4} \bullet\left(\mathrm{H}_{2} \mathrm{O}\right)_{2}$ with any sort of aqueous transition metal chlorides, which can be $\mathrm{FeCl}_{2}$. The product usually is a salt of alkali metal that is splashed with cold water resulting in the drying of mixed metal molybdate. They are further introduced in ammonia and heated to give the ternary nitride. One of the synthetic approaches, [28] which has been investigated during the preparation of numerous ternary nitrides begins with the preparation of the precursors as outlined in the below flow diagram in Figure 1. The stoichiometric molar ratios of the salts are taken, usually weighing of about 6-12 g of metal chlorides, in the glovebox. Thereafter they are added into a $250 \mathrm{ml}$, three-necked round bottom flask accompanied by a magnetic stir bar coated with Teflon.

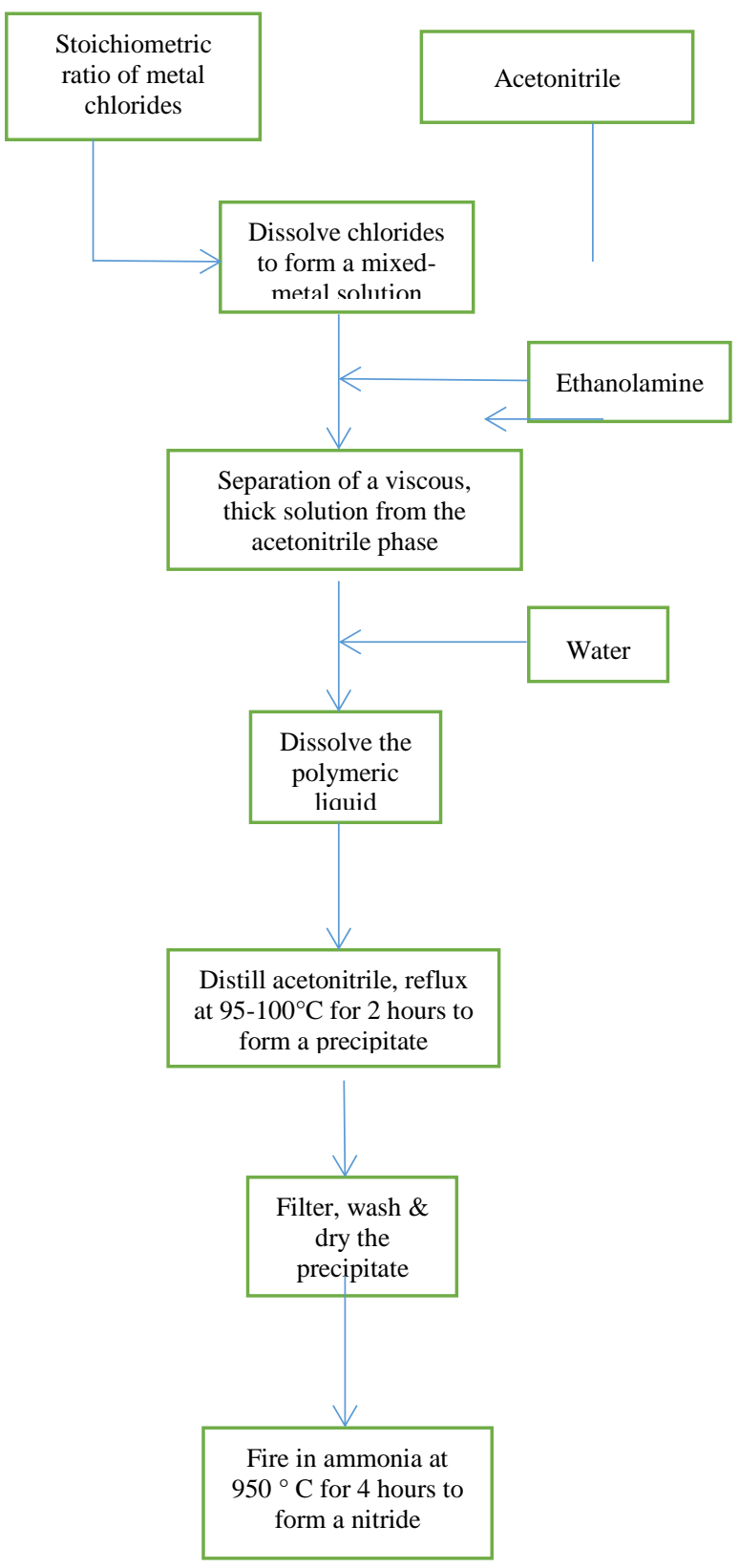

Figure 1: Common protocol for the production of ternary nitrides

The addition of acetonitrile led to the dissolution of the metal chlorides. After that the reaction container is vacuum-packed and at that juncture conveyed to a hood that contains the nitrogen supply and a bubbler at Ultra High Pressure. The ethanolamines were introduced drop wise under constant stirring once the chlorides were completely dissolved.

The amount and character of metal chloride decides the amount of ethanolamine added. In all cases the chelation reactions occurred nearly instantaneously. Sometimes the flask requires 
S. S. Ghani, J. Mod. Mater.; Vol. 4, Issue 1, pp: 10-15, 2017

shaking for several minutes so that it ensures complete dissolution. However on few occasions, in few minutes, the precipitate was formed, indication that hydrolysis has taken place swiftly, whereas in different occasions, the use of cold water get the chelated liquid easily dissolved. The hydrolyzed powders on treatment by heat in ammonia are converted in a single-phase ternary nitride at a very high temperature of around $\sim 1000^{\circ} \mathrm{C}$ in few hours. We may infer that the hydrolysis reaction could bring about the materialization of a compound which is mixed metal hydroxide instead of individual metal hydroxide compounds. Consequently, in an ammonia environment, there was the possibility of substitution of $\mathrm{M}-\mathrm{O}$ bonds as well as breaking down of the hydrocarbons which bring about the production of ternary nitrides in lesser time and at low temperature. [29] We already have the knowledge that the production of ternary nitrides considerably speed up when the hydrocarbons are available during ammonolysis.

\section{Conclusions}

The current progress in the synthesis and characterization of ternary nitrides has led to the finding of a huge number of novel ternary nitrides with new structural features. Because of the experimental challenges in preparation and characterization, the amount of ternary nitride compounds known to date is much less in contrast to their oxide counterparts. Several improvements in the preparation of ternary nitrides have taken place for the past 20 years or so and the amount of completely characterized nitrides is still increasing. The pace of advancement signals that a vast amount of probable nitrides can be synthesized. Numerous innovative and synthetic methodologies have been applied for the preparation of novel ternary nitrides like ammonolysis and amide synthesis. However, ternary nitride chemistry if suitably driven will certainly continue to yield novel structural designs. It is speculated that some of the ternary nitrides are technologically significant due to its unique or superior structural or electronic properties. This review tries to summarize of numerous fields of chemistry of the metal nitrides and gives the vital uses of numerous metal nitrides. Notwithstanding, this is evident that the remarkable growth in the given field since the preceding two decades, considerable work is still to be completed in basic investigations for synthesizing the unidentified nitrides as thriving as in evolving its innovative and prevailing applications. Lastly, this is widely evident that the swelling present-day impetus in chemistry of the ternary metal nitrides is motivating the focus speedily in a new dimension.

\section{How to Cite this Article:}

S. Ghani, "The Development of Ternary Nitride Chemistry During the Last Few Decades", J. Mod. Mater., vol. 4, no. 1, pp. 10-15, Mar. 2017. doi: 10.21467/jmm.4.1.10-15

\section{References}

[1] B. R. Puri, L. R. Sharma, "Principles of Inorganic Chemistry", Shoban Lal Nagin Chand \& Company, Delhi, 569, 1990.

[2] D. A. Headspith, M. G. Francesconi, "Structural Classification of Quasi-One-Dimensional Ternary Nitrides", Inorganics, vol 4, no 4, pp 37-111, 2016.

[3] A. Zakutayev, "Design of nitride semiconductors for solar energy conversion", J. Mater. Chem. A, vol 4, no 18, pp 6742-6754, 2016.

[4] R. Juza, K. Langer, B.K. Von, "Ternary Nitrides, Phosphides, and Arsenides of Lithium", Angew. Chem., Int. Ed.., vol 7, no 5, pp 360-370, 1968.

[5] R. Marchend, Y. Laurent, J. L. Guyader, P. Haridon, P. Verdiir, "Nitrides and oxynitrides: preparation, crystal chemistry and properties", J. Eur. Ceram. Soc., vol 8, no 4, pp 197- 213, 1991.

[6] F. J. DiSalvo, S. J. Clarke, "Ternary nitrides: a rapidly growing class of new materials", Curr. Opin. Solid State Mater. Sci., vol 1, no 2, pp 241-249, 1996.

[7] A. L. Hector, W. Levason, "Chemistry and applications of metal nitrides", Coord. Chem. Rev., vol 257, no 13-14, pp 1945-2142, 2013.

[8] D. H. Gregory, P. M. O'Meara, A. G. Gordon, D. J. Siddons, A. J. Blake, M. G. Barker, T. A. Hamor, P. P. Edwards, "Layered ternary transition metal nitrides; synthesis, structure and physical properties", J. Alloys Compd., vol 317-318, no 12, pp 237-244, 2001.

[9] N. T. Ruiz, M. Segales, D. H. Gregory, "The chemistry of ternary and higher lithium nitrides" Coord. Chem. Rev., vol 257, no 13-14, pp 1978-2014, 2013.

[10] R. S. Pérez, T. F. T. Cerqueira, S. Korbel, S. Botti, M. A. L. Marques, "Prediction of Stable Nitride Perovskites", Chem. Mater., vol 27, no 17, pp 5957-5963, 2015.

[11] K. S. Weil, P. N. Kumta, "Synthesis of ternary transition metal nitrides using chemically complexed precursors", Materials Science and Engineering: B, vol 38, no 1-2, pp 109-117, 1996.

[12] D. H. Gregory, "Structural families in nitride chemistry", J. Chem. Soc., Dalton Trans., no 3, 259-270, 1999.

[13] A. Bowman, R. I. Smith, D. H. Gregory, "Ternary and quaternary layered nitride halides, $\mathrm{Ca}_{2} \mathrm{~N}\left(X, X^{\prime}\right)$ $\left(\mathrm{X}, \mathrm{X}^{\prime}=\mathrm{Cl}, \mathrm{Br}, \mathrm{I}\right)$ : Evolution of structure with composition", J. Solid State Chem., vol 178, no 6, pp 1807 - 1817, 2005. 
[14] S. Kaskel, D. Hohlwein, J. Strahle, "Study of Ammonolysis Reactions within Situ X-Ray Diffraction: Detection and Crystal Structure of $\mathrm{Li}_{0.84} \mathrm{~W}_{1.16} \mathrm{~N}_{2}, J$. Solid State Chem., vol 138, no 1, pp 154-159, 1998.

[15] A. Gomathi, "Ternary Metal Nitrides by the Urea Route", Mater. Res. Bull., vol 42, no 5, pp 870-874, 2007.

[16] F. Mafuné, Y. Tawaraya, S. Kudoh, "Nitrogen Molecule Adsorption on Cationic Tantalum Clusters and Rhodium Clusters and Desorption from Their Nitride Clusters Studied by Thermal Desorption Spectrometry", J. Phys. Chem. A., vol 120, no 24, pp 4089 - 4095, 2016.

[17] J. Xie, Y. Xie, "Transition Metal Nitrides for Electrocatalytic Energy Conversion: Opportunities and Challenges", Chem. Eur. J., vol 22, no 11, pp 35883598, 2016.

[18] Y. Zhong, X. Xia, F. Shi, J. Zhan, J. Tu, H. J. Fan, "Transition Metal Carbides and Nitrides in Energy Storage and Conversion", Adv. Sci., vol 3, no 5, pp 1-28, 2016.

[19] S. H. Yoo, A. Walsh, D. O. Scanlon, A. Soon, "Electronic structure and band alignment of zinc nitride, $\mathrm{Zn}_{3} \mathrm{~N}_{2}{ }^{\prime}$, RSC Adv., vol 4, no 7, pp 3306-3311, 2014.

[20] S. T. Oyama, "Introduction to the chemistry of transition metal carbides and nitrides", The Chemistry of Transition Metal Carbides and Nitrides, Chapman \& Hall, pp 1-27, 1996.

[21] J. C. Scho"n, M. A. C. Wevers, M. Jansen, "Investigation of the possible ternary nitrides in the system Li3N/Na3N", Solid State Sci., vol 2, no 4, pp 449-456, 2000.

[22] M. G. Barker, I. C. Alexander, "Reactions of lithium nitride with cerium, thorium, and hafnium: formation of $\mathrm{Li}_{2} \mathrm{CeN}_{2}, \mathrm{Ce}_{2} \mathrm{~N}_{2} \mathrm{O}, \mathrm{Li}_{2} \mathrm{ThN}_{2}$, and $\mathrm{Li}_{2} \mathrm{HfN}_{2}$ ", J. Chem. Soc. Dalton Trans., no 20, pp 2166-2170, 1974.

[23] A. Yamada, S. Matsumoto, Y. Nakamura, "Direct solidstate synthesis and large-capacity anode operation of $\mathrm{Li}_{3-\mathrm{x}} \mathrm{Fe}_{x} \mathrm{~N}$ ", J. Mater. Chem., Vol 21, no 27, pp 1002110025, 2011

[24] F. Liang, L. Tian, H. Zhang, F. Liang, S, Liu, R Cheng, S. Zhang, "Low temperature synthesis of LiSi2N3 nanobelts via molten salt nitridation and their photoluminescence properties", $R S C A d v$., vol 6, no 73, pp 68615-68618, 2016.

[25] M. G. Barker, M. G. Francesconi, P. M. O’Meara, C. F. Baker," New synthetic routes to transition metal ternary nitrides and sulfides", J. Alloys Compd., vol 317-318, pp 186-189, 2001.

[26] J. D. Houmes, S. Deo, H. C. L. Zur, "Synthesis and Characterization of the New Ternary Nitride $\left(\mathrm{Fe}_{0.8} \mathrm{~W}_{0.2}\right)$ $\mathrm{WN}_{2}$ ", J. Solid State Chem., vol 131, no 2, pp 374-378, 1997.

[27] B. Mazumder, A. L. Hector, "Synthesis and applications of nanocrystalline nitride materials", J. Mater. Chem., vol 19, no 27, 4673- 4686, 2009.

[28] F. A. Cotton, G. Wilkinson, Advanced Inorganic Chemistry, Wiley, New York, 1988.

[29] S. H. Elder, F. J. DiSalvo, L. Topor, A. Navrotsky, "Thermodynamics of ternary nitride formation by ammonolysis: application to lithium molybdenum nitride (LiMoN2), sodium tungsten nitride (Na3WN3), and sodium tungsten oxide nitride (Na3WO3N)" Chem. Mater., vol 5, no 10, pp 1545-1553, 1993.
Publish your research article in AIJR journals-

$\checkmark$ Online Submission and Tracking

$\checkmark$ Peer-Reviewed

$\checkmark$ Rapid decision

$\checkmark \quad$ Immediate Publication after acceptance

$\checkmark$ Articles freely available online

$\checkmark \quad$ Retain full copyright of your article.

Submit your article at journals.aijr.in

Publish your books with AIJR publisher-

$\checkmark \quad$ Publish with ISBN and DOI.

$\checkmark$ Publish Thesis/Dissertation as Monograph.

$\checkmark$ Publish Book Monograph.

$\checkmark$ Publish Edited Volume/ Book.

$\checkmark \quad$ Publish Conference Proceedings

$\checkmark \quad$ Retain full copyright of your books.

Submit your manuscript at books.aijr.org 